\title{
A STUDY ON IV LABETALOL VERSUS ORAL NIFEDIPINE IN ACUTE CONTROL OF SEVERE HYPERTENSION IN PREGNANCY
}

KEY WORDS: Pre eclampsia. Oral Nifedipine, IV Labetalol, efficacy.

\section{Dr. G. Kesava Chandra general hospital, kadapa.

Objective: To compare the efficacy of IV Labetalol with oral Nifedipine in the treatment of severe hypertension in pregnancy with blood pressure $>160 / 110 \mathrm{~mm} \mathrm{Hg}$.

Methods: A parallel double blinded randomized control trial between Jan 2019 and May 2019 in 100 antenatal women of gestational age $>28$ weeks, admitted with blood pressure $>160 / 110 \mathrm{~mm} \mathrm{Hg}$ conducted in labour ward tertiary hospital. Antenatal women were randomized to receive oral Nifedipine 10mg tablet orally up to 5 doses and IV Labetalol was initiated at $20 \mathrm{mg}$ and in escalating doses of $20 \mathrm{mg}$, $40 \mathrm{mg} .80 \mathrm{mg}$, and $80 \mathrm{mg}$ up to $220 \mathrm{mg}$. The number of doses and meantime taken to achieve target blood pressure $<140 / 90 \mathrm{~mm} \mathrm{Hg}$ was noted.

Results: hundred antenatal women were randomized to 50 in each group. In the Labetalol group 5 patients required oral Nifedipine to achieve target blood pressure but none in the Nifedipine group. The numbers of doses required and meantime taken to achieve target bloodpressure in nefidipine group were less compared to that of Labetalol group.

Conclusion: IV Labetalol and oral Nifedipine were equally effectively to achieve target blood pressure. Incomparsion, oral Nifedipine achieved target blood pressure more quickly than Labetalol.

\section{INTRODUCTION:}

Hypertension in pregnancy, called a disease of degree is more of a sign than a disease by itself. With various advancements in the pathophysiology and various insights into the prevention of this disease, effective and timely control of hypertension is still the most imperative step in the management. Concerns akin to maternal morbidity, mortality and fetal and neonatal outcomes imply the impact of the disease in the obstetric population. The recent management option explores the various modalities in prediction and prevention of hypertension in pregnancy. However, the only effective therapy is the delivery of the fetus and placenta. The ancillary therapy is principally symptomatic and not directed at the fundamental cause. Effective pharmacologic therapy modifies the course of the disease. The effective use of antihypertensive therapy should be based on well designed controlled clinical trials and the experience of the clinician with the drugs. Hypertensive disorders complicate $5-10 \%$ of all pregnancies worldwide.(1)

Labetalol was studied for its use in treatment of hypertensive urgencies in the general population. The smooth onset of action with minimal change in cardiac output and heart rate makes it a unique drug in the management of hypertensive emergency in pregnancy. Nifedipine has been evaluated for its immediate onset of action and ease of administration and no reported adverse effects on the mother or the foetus and on the course of labour. This study ventures to compare the pharmacodynamics of intravenous Labetalol and oral Nifedipine in patients with severe hypertension and to compare the maternal and foetal outcomes and adverse effects of both the drugs. (2)

\section{AIM AND OBJECTIVE OFTHE STUDY:}

- A recent CEMACH report recommends urgent and effective anti hypertensive treatment for patients with severe hypertension in pregnancy.

- Both intravenous Labetalol and oral Nifedipine (3) are used in acute blood pressure control in severe hypertension.

- The aim of the study is to compare intravenous Labetalol with oral Nifedipine in the management of acute blood pressure control in hypertensive emergencies of pregnancy.

- The present study is undertaken to compare the efficacy of IV Labetalol with oral Nifedipine in the treatment of Severe hypertension in pregnancy with blood pressure $\geq 160 / 110 \mathrm{~mm} \mathrm{Hg}$

\section{Definition:}

Hypertension in pregnancy goes by the definition of a sustained systolic blood pressure of $140 \mathrm{~mm} \mathrm{Hg}$ or more and/or a diastolic blood pressure of $90 \mathrm{~mm} \mathrm{Hg}$ or more detected for the first time during pregnancy after 20 weeks of gestational age.(4)

The working group classification of hypertension in pregnancy is as follows.

\section{Gestational hypertension}

2.Preeclampsia

3.Eclampsia

4.Preeclampsia superimposed on chronic hypertension 5. Chronic hypertension

The presence of the following features suggests the increased certainty of preeclampsia.

\section{- Blood pressure of $\geq 160 / 110 \mathrm{~mm} \mathrm{Hg}$}

- Proteinuria of $\geq 2 \mathrm{~g} /$ day or a dipstick proteinuria estimation of $\geq 2+$

- Newly detected rise in serum creatinine level of $>1.2$ $\mathrm{mg} / \mathrm{dl}$

- Thrombocytopenia, with platelet count $<1,00,000 / \mathrm{L}$

- Increased serum lactate dehydrogenise levels indicating microangiopathic haemolysis

- Elevated liver enzymes

- Persistent headache and visual disturbances

- Persistent epigastric pain

Severe preeclampsia is defined as severe hypertension with proteinuria or hypertension with severe proteinuria constituting $5 \mathrm{~g} /$ day or more. The definition includes multisystem involvement and also comprises imminent signs and symptoms (5).

\section{Labetalol}

First of its kind, is a combined - and -adrenergic blocker. The chemical formulation contains four stereoisomers with distinct action profiles on the receptor subtypes. The

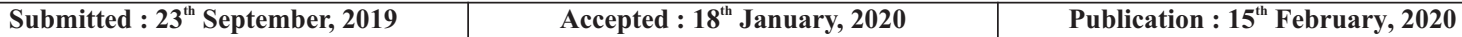

|www.worldwidejournals.com 31 
available commercial preparation is a racemic mixture of two pairs of chiral isomers.

- Labetalol Pharmacokinetics

- $100 \%$ bioavailability following i.v. administration

onset of action following i.v.is 2.5 minutes

peak action at 5 minutes

- $50 \%$ plasma protein bound

- $\mathrm{T} 1 / 2$ is 4.9 hours

- Target concentration is $0.1 \mathrm{mg} / \mathrm{dl}$

- Metabolized in liver via conjugation to glucuronide metabolites. (6)

Nifedipine effectively dilates the arterioles in preference to veins thus producing an effective vasodilatation without producing postural hypotension.

It reduces the total peripheral resistance and thereby reduces the after load

- Pharmacokinetics of Nifedipine

- $45-70 \%$ oral bioavailability

- Onset of action in 20 minutes

- peak action in 0.5 to 1 hour

- Tl/2is 4 hours

- duration 4 to 8 hours

- Metabolized in the liver

- Excretion via renal $80 \%$ and faeces $20 \%$

- No need for dose reduction in renal disorders. (7)

\section{Materials and methods:}

The study was conducted in a tertiary care teaching institution, Government General Hospital, Kadapa in the Department of Obstetrics and Gynaecology during the period of January 2019 to May 2019.

One hundred consecutive patients satisfied the inclusion criteria were recruited in the present study.

\section{Inclusion Criteria}

- Age- 18 to 35 years,

- All pregnant women of 20 weeks gestation or more; excluding parity and booking status

- Singleton pregnancy

- Sustained severe hypertension: Systolic blood pressure $\geq$ $160 \mathrm{~mm} \mathrm{Hg}$; diastolic blood pressure $\geq 110 \mathrm{~mm} \mathrm{Hg}$

\section{Exclusion Criteria}

- Eclampsia;HELLP syndrome

- Bronchial asthma

- Cardiac failure

- Cardiac rhythm abnormalities

- Chronic hypertension

- Co-existent diseases like diabetes mellitus, rheumatic heart disease, congenital heart disease, renal or hepatic disorders

\section{History}

A thorough history was elicited from the patients regarding age, parity, socio economic status, booking history, history suggestive of imminent symptoms. Their past history regarding bronchial asthma, cardiac diseases, prior drug intake for hypertension and other medical disorders were also obtained

\section{Clinical examination}

- A meticulous general examination and obstetric examination were carried out.

- On general examination, patients level of consciousness, degree of anaemia, edema, jaundice, pulse rate, respiratory rate and temperature were ascertained.
- Blood pressure measurement was done with the mercury sphygmomanometer with the patient lying at an angle of 45 degrees.

- The mercury manometer placed at the level of patients' heart. The measurements were taken in the right arm.

- The fifth Kortokoff, K5 sound was taken for diastolic blood pressure cut off.

- When K5 was not heard, muffling of the sound, K4 was considered.

- Systemic examination and obstetric examination were carried out.

\section{Investigations}

- Urine analysis

- Complete blood count including platelet count

- Blood grouping and typing

- Renal function tests

- Liver function tests

- Peripheral smear study

\section{Anti-hypertensive management}

- Group A

- Fifty patients were selected consecutively according to random numbers to receive the package containing intravenous Labetalol injection in escalating doses of 20 $\mathrm{mg}, 40 \mathrm{mg}, 80 \mathrm{mg}, 80 \mathrm{mg}$ (up to $220 \mathrm{mg}$ ) and a placebo tablet for every fifteen minutes until the target Group B

- Fifty patients were randomized to receive the package containing Nifedipine $10 \mathrm{mg}$ tablet orally every fifteen minutes and intravenous placebo saline injections of $4 \mathrm{ml}$, $8 \mathrm{ml}, 16 \mathrm{ml}, 16 \mathrm{ml}, 16 \mathrm{ml}$ up to five doses till the target blood pressure of $\leq 140 / \leq 90 \mathrm{~mm} \mathrm{Hg}$ was achieved.

- Blood pressure of $\leq 140 / \leq 90 \mathrm{~mm} \mathrm{Hg}$ was achieved.

- The drug regime was crossed over to the other group if the initial regime was found unsuccessful after five cycles and blood pressure monitoring done.

- Patient was made to rest in bed in left lateral position.

- Blood pressure was noted every 15 minutes. Once the blood pressure was $<140 / 90 \mathrm{~mm} \mathrm{Hg}$, no further trial medication was given until two consecutive readings were $>$ 160/110 mm Hg.

\section{Outcome measures}

- The primary outcome of this trial was the time taken to achieve a target blood pressure of $\leq 140 \mathrm{~mm} \mathrm{Hg}$ systolic and $\leq 90 \mathrm{~mm} \mathrm{Hg}$ diastolic in both the groups. Both had to be achieved.

- The secondary outcome measures include total number of antihypertensive doses to achieve the target blood pressure, both systolic and diastolic.

\section{Statistical analysis}

- All the data were entered consecutively in a predefined data information sheet and analysis was done using SPSS 20 software.

- Differences in categorical and continuous data were assessed using the Chi square test and Student't' test, respectively.

- The tests were two sided. The statistical test is considered significant if the calculated $\mathrm{p}$ value is less than 0.05 .

\section{RESULTS}

\section{Age Distribution}

There is no significant difference in ages of the recruited patients in both the groups. The mean age in Labetalol and Nifedipine groups was 24.89 and 24.81 years respectively. The majority of the patients had an age belonging to the category of 21 to 29 years. $18 \%$ and $24.50 \%$ from group $A$ and group B respectively had ages 20 years and below 


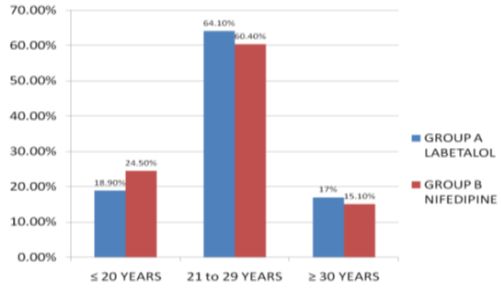

Figure 1: Distribution based on age

\section{PARITY}

- Parity was comparable in group A and group B.There is no significant difference in the parity of both the groups.

- Majority of the patients constituting $78 \%$ of group $\mathrm{A}$ and $52 \%$ of group B were primigravida.

- $65 \%$ enrolled in the study were primigravida. There is a higher incidence of preeclampsia in the first pregnancy

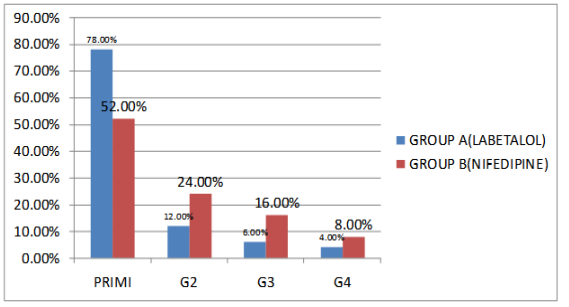

\section{Figure 2: Distribution based on parity}

\section{BOOKING STATUS}

- The antenatal booking status did not differ significantly in both the groups. $14 \%$ and $18 \%$ from group $A$ and B respectively were unbooked.

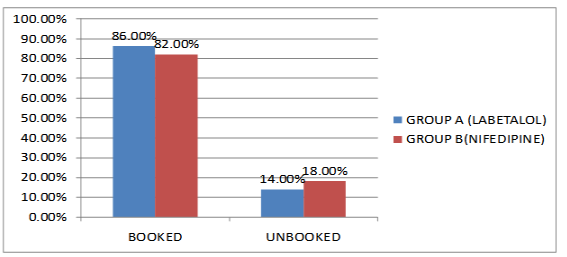

Figure 3: comparison of two groups based on booking status

\section{GESTATIONAL AGE:}

- The majority of the patients had gestational age of 34 to 36 weeks constituting $41 \%$ on the whole with $42 \%$ and $40 \%$ respectively in group $A$ and $B$.

- The recruited patients did not significantly differ in gestational age

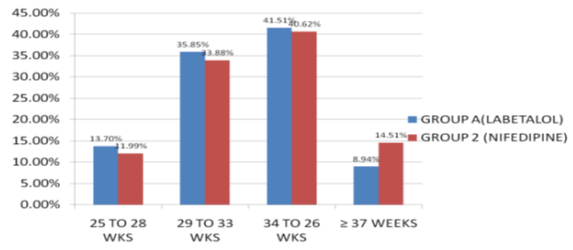

Figure 4: comparison of two groups based on gestational age

\section{BODY MASS INDEX}

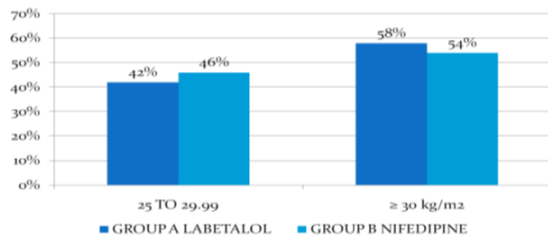

Figure 5: comparison of two groups based on BIMI
- $56 \%$ had a body mass index exceeding 30 belonging to the category obesity.

- There is no significant difference in the body mass index between the two groups.

\section{SYSTOLIC BLOOD PRESSURE}

- The baseline systolic blood pressure of the patients recruited in both the groups did not differ significantly.

- The mean systolic blood pressure in intravenous Labetalol group was $171 \mathrm{~mm} \mathrm{Hg}$ whereas it was $170 \mathrm{~mm} \mathrm{Hg}$ in oral Nifedipine group.

- $40 \%$ of patients in group $A$ had a blood pressure range of 160 to $169 \mathrm{~mm} \mathrm{Hg}$.

- $52 \%$ of patients in Nifedipine group had a blood pressure range of 170 to $179 \mathrm{~mm} \mathrm{Hg}$

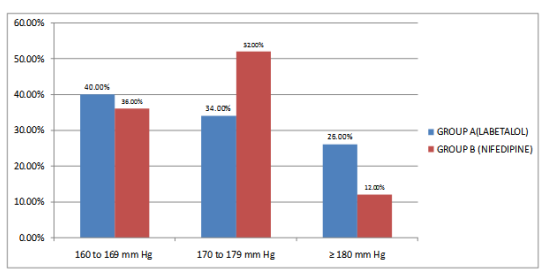

Figure 6: Comparison Of Two Groups Based On Systolic BP

\section{DIASTOLIC BLOODPRESSURE:}

- The baseline diastolic blood pressure did not vary significantly in the groups.

- The mean of the baseline diastolic blood pressure were $112 \mathrm{~mm} \mathrm{Hg}$ and $111 \mathrm{~mm} \mathrm{Hg}$ in the groups A and B, respectively.

- $74 \%$ and $72 \%$ in groups A and B had diastolic blood pressure more than $110 \mathrm{~mm} \mathrm{Hg}$

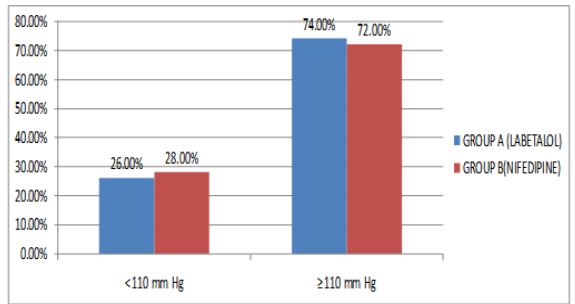

Figure 7: Comparison Of Two Groups Based On Diastolic BP

TIME TAKEN TO ACHIEVE TARGET BLOOD PRESSURE $42 \%$ of patients enrolled in group $A$ reached the target blood pressure on administration of three consecutive doses of antihypertensive, while $42 \%$ of that in group B achieved target blood pressure in two doses of the drug administered. But the difference is not statistically significant

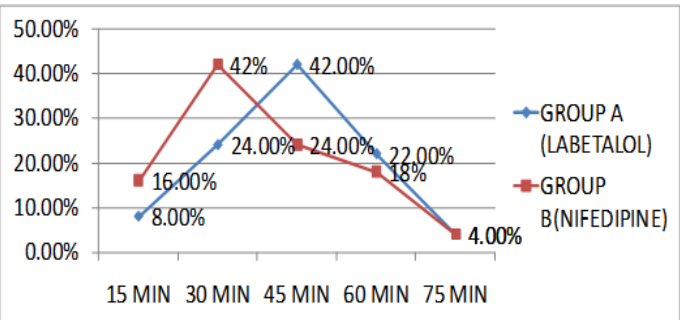

Figure 8: Time Taken To Achieve Target Blood Pressure

\section{DISCUSSION}

Hypertensive emergency in pregnancy is associated with a considerable morbidity and mortality in both maternal and neonatal populations.

The primary aim is to reduce the dangerously elevated blood pressure and ameliorate the severity of the disease. 
In the present study, intravenous Labetalol was compared with oral Nifedipine in terms of efficacy and safety.

The patients enrolled in both the groups were comparable in terms of age, parity, booking status, gestational age at admission and body mass index.

The mean age of the patients enrolled in the study was 24.89 years and 24.81 years in Labetalol and Nifedipine groups respectively

According to the study by Duckitt et al, prim parity is one of the risk factors for preeclampsia. (8)

In the present study, $78 \%$ of Labetalol group and $52 \%$ of Nifedipine group were primigravida.

In the present study $41 \%$ patients presented in the gestational age of 34 to 36 weeks

In a randomized control trial conducted by Saibai, Brian, et al, on the expectant management of severe preeclampsia, the blood pressure on admission was found to be $>160 / 110$ mmhg.(9)

The mean systolic blood pressure of the patients enrolled in the Labetalol and Nifedipine groups in the present study was $171 \mathrm{~mm} \mathrm{Hg}$ and $170 \mathrm{~mm} \mathrm{Hg}$, respectively.

The mean diastolic blood pressure was 112 and $111 \mathrm{~mm} \mathrm{Hg}$ in Labetalol and Nifedipine groups, respectively admission was found to be $\geq 160 / 110 \mathrm{~mm} \mathrm{Hg}$.

\section{SUIMIMARY}

- In the present study, out of the 100 antenatal patients with sustained severe hypertension, 50 were randomized to receive intravenous Labetalol treatment and the rest were randomized to oral Nifedipine treatment and the two groups were compared in terms of efficacy of the treatment.

- All the patients recruited in the study achieved blood pressure control. Majority of the patients in Labetalol group ( $42 \%$ ) achieved target blood pressure at 45 minutes and that with the Nifedipine group (42\%) achieved the target blood pressure at 30 minutes

- $25.80 \%$ in Labetalol group received three doses of the drug. $26.40 \%$ of the patients received two doses of the drug in Nifedipine group.

- The rate of fall of blood pressure was the highest at 45 minutes for Labetalol group and at 30 minutes for the Nifedipine group.

- None of the patients had hypotensive episodes. There were no instances of foetal cardiotocographic abnormalities during the trial period.

- Both the groups exhibited significant differences in heart rate after 30 minutes of the commencement of the treatment. The heart rate declined with respect to time in the Labetalol group. There was a rise in heart rate in the Nifedipine group.

\section{CONCLUSION}

In the present study, the trend in reduction of blood pressure in patients with sustained severe hypertension with the use of intravenous labetalol and nifedipine was compared.

From the present study, both the drugs were found to be safe and effective in the reduction of blood pressure.

Intravenous labetalol provided a smooth and steady reduction in blood pressure. The use of nifedipine may be recommended in low resource settings since it has an oral regimen and dosage is simple when compared to incremental intravenous dosing of labetalol.
In conclusion, both intravenous labetalol and oral nifedipine are equally efficacious and can be used as first line drugs for the use in acute blood pressure control of hypertensive emergency of pregnancy.

\section{REFERENCES:}

1. Cunningham F, Leveno KJ, Bloom SL, Hauth JC, Rouse DJ, Spong CY.Pregnancy hypertension. In: Dashe JS, Hoffman BL, editors. Williams Obstetrics. 23rd ed. NewYork:McGraw-Hill.2010.p.706-7.

2. Lewis G. The Confidential Enquiry into Maternal and Child Health (CEMACH). Saving Mother's Lives: Reviewing Maternal Deaths to Make Motherhood Safer - 2003-2005. The Seventh Report on Confidential Enquiries into Maternal Deaths in the United Kingdom. London: CEMACH, 2007.

3.. Duley L, Henderson-Smart DJ, Meher S. 2006. Drugs for the treatment of very high blood pressure during pregnancy. Cochrane Database of Syst Rev 2006;3:CD001449.

4. Report on the National High Blood Pressure Working Group on High Blood Pressure in Pregnancy. Am J Obstet Gynecol.2000;183:S1

5.. Gustaaf D. Hypertension. In: James D, Steer PJ, editors. High risk pregnancy management options. 4th ed. Missouri:Saunders Elsevier.2011.p. 600.

6. Mabie WC, Gonzalez AR, Sibai BM, et al. A comparative trial of labetalol and hydralazine in the acute management of severe hypertension complicating pregnancy. Obstet Gynecol. 1987;70:328.

7. Sibai BM, Barton JR, Sherif AKL, Sarinoglu C, Mercer BM. A randomized prospective comparison of nifedipine and bed rest versus bed rest alone in the management of preeclampsia remote from term. A randomized prospective comparison of nifedipine and bed rest versus bed rest alone in the management of preeclampsia remote from term. 1992; 167:879-884.

8. . Duckitt K, Harrington D. Risk factors for preeclampsia at antenatal booking: a systemic review of controlled studies. Br Med J.2005 Mar 12;330(7491):565.

9. Sibai, B. M., Mercer, B. M., Schiff, E., \& Friedman, S. A. Aggressive versus expectant management of severe preeclampsia at 28 to 32 weeks' gestation:a randomized controlled trial. American journal of obstetrics and gynecology. $1994 ; 171(3): 818-22$ 